\title{
Functional and radiological outcomes of distal humerus fractures treated with pre-contoured locking compression plate
}

\author{
Pravin K. Vanchi, Raghav R. V.*, Mohan Kumar M.
}

Department of Orthopedics, Sri Ramachandra Institute of Higher Education and RI, Chennai, Tamil Nadu, India

Received: 19 December 2021

Revised: 03 January 2022

Accepted: 04 January 2022

\author{
*Correspondence: \\ Dr. Raghav R. V., \\ E-mail: raghavravi2193@gmail.com
}

Copyright: ( ) the author(s), publisher and licensee Medip Academy. This is an open-access article distributed under the terms of the Creative Commons Attribution Non-Commercial License, which permits unrestricted non-commercial use, distribution, and reproduction in any medium, provided the original work is properly cited.

\begin{abstract}
Background: Distal humerus intra-articular fractures are one of the complicated fractures managed by orthopaedic surgeons. We did a prospective and a retrospective study on 21 patients with these fractures treated with pre-contoured locking compression plate.

Methods: The 21 patients in this series were followed for a minimum of 1 year. The prospective study cases were followed at 3 months, 6 months and annually. The rating system of the Mayo elbow functional scoring system was used. The radiological evaluation was done using standard AP and lateral views.

Results: We had 14 patients with range of motion of 50-100 degrees. There was only one patient with range of motion of $<50$ degrees. 6 patients had the maximum range motion of $>100$ degrees. We had $6(23.57 \%)$ excellent, $9(42.85 \%)$ good, $5(23.80 \%)$ fair and $1(4.7 \%)$ poor in the Mayo elbow scoring at the end of 1 year. We were able to compare our outcomes with a study done by Kumar et al done in 2017. They had $27(89.66 \%)$ of excellent and good results as opposed to $27(79.4 \%)$ in our study. Out of 21 patients in our study $17(80.95 \%)$ patients had good $11(52.5 \%) /$ excellent $6(28.5 \%)$ results. This was comparable with Jupiter et al. His study of 34 patients $26(79.40 / 0)$ patients showed good $14(41 \%)$ / excellent $13(38.4 \%)$ result.

Conclusions: Pre-contoured locking compression plate appears to be technically an ideal implant for comminuted osteoporotic bone providing an angle stable construct.
\end{abstract}

Keywords: Distal humerus, Pre contoured plates, Olecranon osteotomy

\section{INTRODUCTION}

Distal humerus intra-articular fractures are one of the complicated fractures managed by orthopaedic surgeons. They comprise approximately $2 \%$ of all fractures in adults. ${ }^{1}$ They follow bimodal distribution, with low energy fractures occurring in older individuals and high energy fractures in younger people. Osteoporosis and comminution of fracture render internal fixation difficult.

The complex anatomy of elbow joint, displaced multiple fragments and intra-articular extension of fracture make these cases challenging to treat and carry a high complication rate. Early attempts at open reduction and internal fixation of these difficult fractures fell into disrepute because of inability to obtain a stable fixation which led to prolonged postoperative immobilisation.

Articular surface should be reconstituted anatomically and fixed rigidly to attain useful function of the elbow joint. The only reliable method for restoring the normal alignment and contour of the distal humerus is operative exposure and direct manipulation of the fracture fragments and internal fixation using screws and plates. ${ }^{2}$

We did a prospective and a retrospective study on 21 patients with these fractures in Sri Ramachandra University from 2016 to 2018. 


\section{METHODS}

The aim was to study the functional and radiological outcome of 21 patients who had an intra-articular distal humerus fractures treated with pre-contoured locking compression plates. It was a both prospective and retrospective study done at Sri Ramachandra institute of higher education and research (SRIHER) between 2018 and 2021. All patients with closed intra-articular distal humerus fractures, patients 18 years of age and above, patients with uni-columnar fixation treated only with precontoured locking compression plate, patients with bicolumnar fixation treated with pre-contoured locking compression plate in both the columns were all included in study. Ethical clearance was obtained from the institution prior to the study. The sample size was not determined before the study and the cases were included as when the implant was used for the fractures. Compound fractures and fractures which are more than 6 weeks old are not included in the study. Even patients who were treated initially by means of native splinting and patients with ipsilateral humerus fractures were not included in the study.

The age group varied from 25 years to 63 years. Incidence of fracture was maximum observed in 31-50 years of age. Among the 21 cases, males were predominant when compared to females. Commonest mode of injury were road traffic accidents (11 patients)-including motorcycle accidents, motor vehicle accidents and one pedestrian. Fall on outstretched hand were also close enough with 10 patients. Right sided injuries were more common than left side. The extent to which the side is injured with respect to the patient's dominant side was also compared. The maximum fractures were of the $\mathrm{AO}$ classification $\mathrm{C} 2$ type (9 fractures), followed by $\mathrm{C} 1$ (7 fractures) and $\mathrm{C} 3$ (5 fractures) (Figure 1).

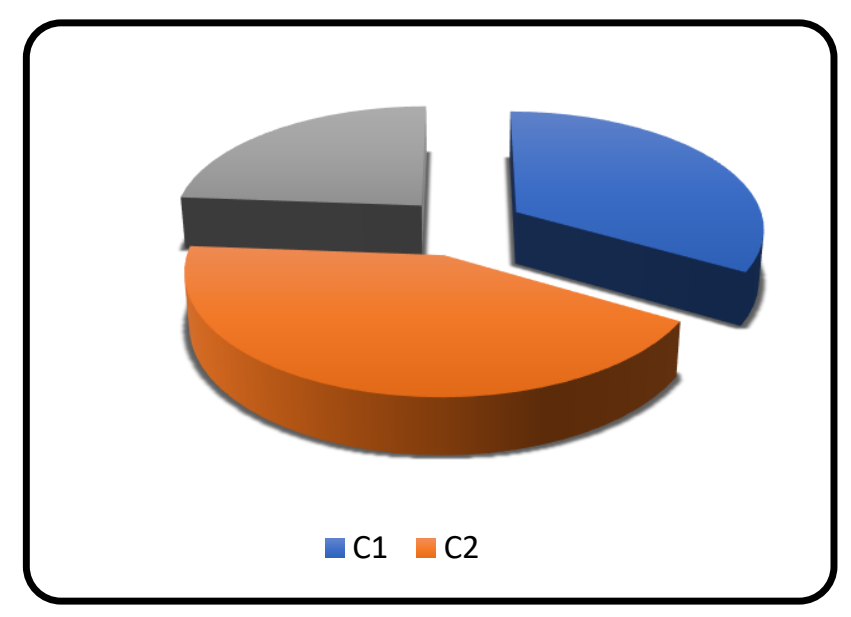

Figure 1: Fracture type.

After obtaining an informed consent, a thorough clinical examination was done as per predesigned and pre-tested proforma which include age, sex, occupation, mode of injury, type of fracture, time interval between injury and surgery, associated comorbid conditions and other associated injuries. X-ray elbow AP/Lateral view from the middle of humerus to the forearm was taken for all the 21 patients and the following features were assessed: type of fracture, amount of comminution, articular congruence and quality of bone. All other requisite $\mathrm{x}$-rays to rule out other injuries were also taken. As and when required a computerized tomography of the elbow joint with 3D reconstruction was also taken to assess the fracture pattern. It also aided in the approach required and the column to be plated. The associated fractures such as facial bone fractures and lower limb fractures were also documented.

All fractures were fixed through triceps reflecting anconeus preserving approach (TRAP) with patient in the lateral position. The ulnar nerve was isolated and retracted in 20 patients and was trans-positioned anteriorly in 1 patient. The operative time averaged between one and half hours to two hours.

Proper rehabilitation is given to attain a satisfactory range of motion, strength, and function of the elbow. Range of motion exercises are started on 2 nd day as tolerated by the patient. Flexors and extensors of the elbow are stretched. Passive mobilization of the elbow was started following that and it showed a gradual increase in the motion of the elbow.

The 21 patients in this series were followed for a minimum of 1 year. The prospective study cases were followed at 3 months, 6 months and annually. The shortest follow up was 1 year and the longest was 2 years with a mean follow up of 16 months. Each patient completed a comprehensive questionnaire regarding functional capabilities, residual symptoms, existing disabilities and was examined by one or several of us. AP and lateral radiographs of the involved elbow were made at the follow up examination. The rating system of the Mayo elbow functional scoring system was used. The data on elbow motion were combined with the patient's subjective symptoms to provide an overall functional rating. The radiological evaluation was done using standard anteroposterior and lateral views of distal humerus.

It was a description study and statistical analysis was done based on Pearson's chi-square tests.

\section{RESULTS}

We had 14 patients with range of motion of 50-100 degrees. There was only one patient with range of motion of $<50$ degrees. 6 patients had the maximum range motion of $>100$ degrees.

The Mayo elbow scoring system was used, this system is easy to follow and easy to analyse. It takes into account pain, arc of motion, functional outcome. We had 6 $(23.57 \%)$ excellent, $9(42.85 \%)$ good, $5(23.80 \%)$ fair and $1(4.7 \%)$ poor in the Mayo elbow scoring at the end of 1 year (Figure 3). 


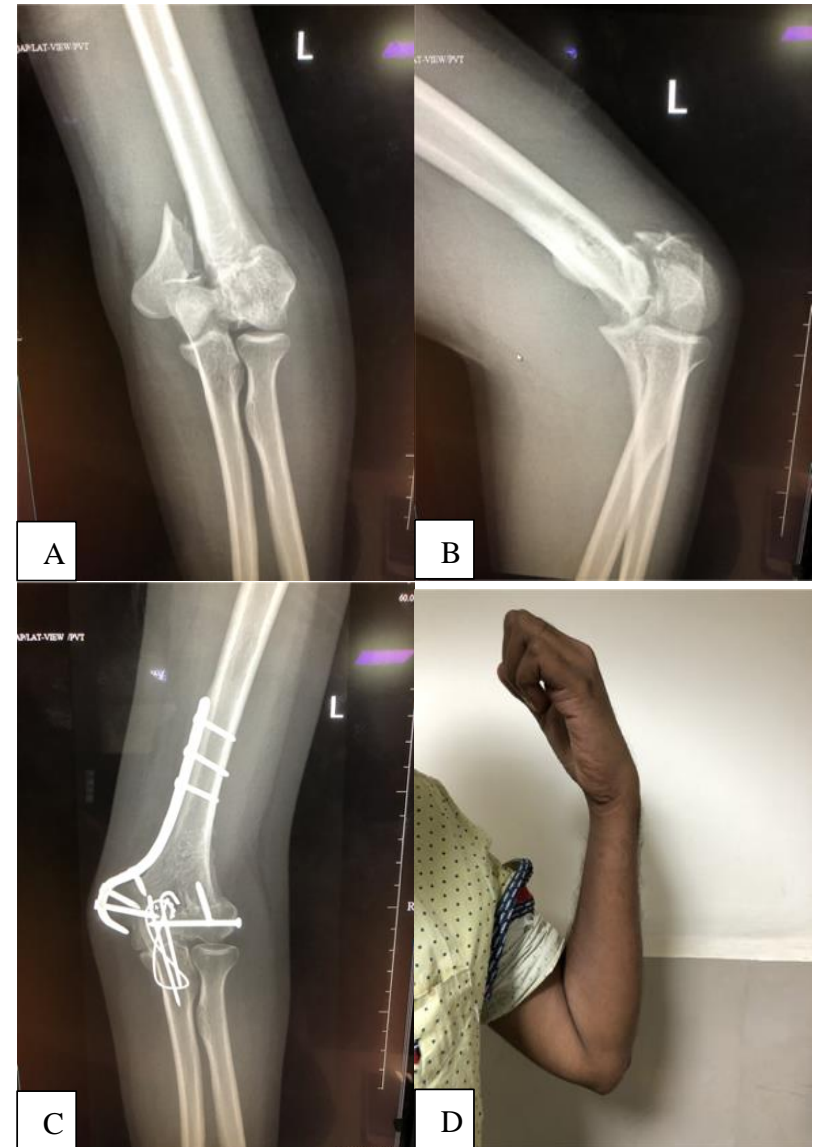

Figure 2 (A-D): Excellent outcome with good range of movements at the end of one year.

The Mayo score for each fracture type was tabulated and evaluated (Table 1).

The two main complications in our study were ulnar nerve neuritis and $\mathrm{K}$ wire back out from the TBW fixation which was done for the osteotomy. Appropriate management was done for each of these complications. Two of the $\mathrm{C} 2$ fractures had ulnar nerve neuritis and one $\mathrm{C} 1$ fracture had a complication of $\mathrm{K}$ wire backout (Figure 4).

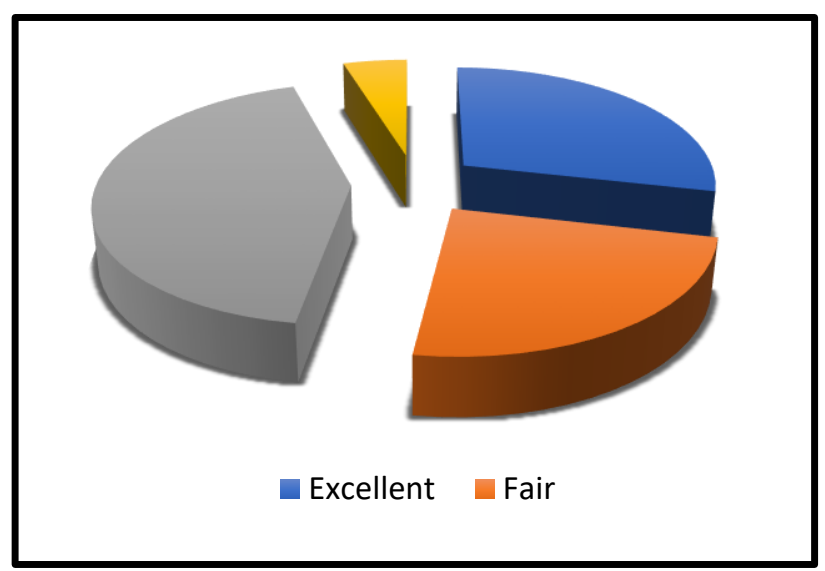

Figure 3: Mayo score-1 year.

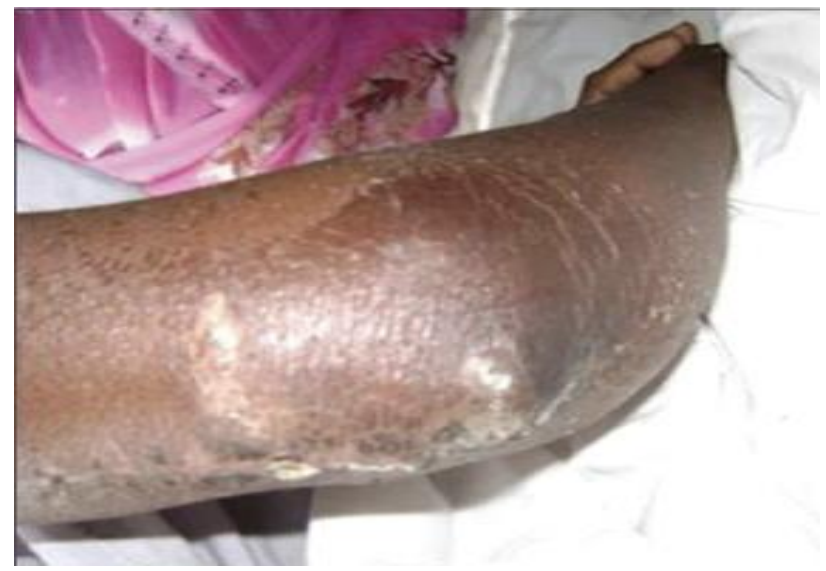

Figure 4: K wire back out as a complication.

Table 1: Mayo score with respect to fracture type.

\begin{tabular}{|c|c|c|c|c|c|c|c|}
\hline \multirow{2}{*}{ Variables } & & & \multicolumn{4}{|c|}{ Mayo 1 year } & \multirow{2}{*}{ Total } \\
\hline & & & Excellent & Fair & Good & Poor & \\
\hline \multirow{6}{*}{ Fracture type } & \multirow{2}{*}{$\mathrm{C} 1$} & Count & 2 & 1 & 4 & 0 & 7 \\
\hline & & $\%$ & 33.3 & 20 & 44.4 & 0. & 33.3 \\
\hline & \multirow{2}{*}{$\mathrm{C} 2$} & Count & 3 & 2 & 4 & 0 & 9 \\
\hline & & $\%$ & 50 & 40 & 44.4 & 0 & 42.9 \\
\hline & \multirow{2}{*}{ C3 } & Count & 1 & 2 & 1 & 1 & 5 \\
\hline & & $\%$ & 16.7 & 40 & 11.1 & 100 & 23.8 \\
\hline \multirow{2}{*}{ Total } & & Count & 6 & 5 & 9 & 1 & 21 \\
\hline & & $\%$ & 100 & 100 & 100 & 100 & 100 \\
\hline
\end{tabular}

\section{DISCUSSION}

This study was concluded on 21 patients with closed inter condylar fracture of distal humerus in patients with age group 18 and above at Ramachandra medical college and research institute, Chennai from 2018-2021. There have been numerous studies regarding the management of this uncommon fracture. The fracture has been classified by varying criteria, and the results have been judged by a wide range of methods of functional evaluation. Our study presents the results of a consistent, controlled surgical treatment using pre-contoured locking compression plates at a single institution, making use of current operative techniques, equipment and controlled post-operative mobilization. 
Although there are a number of classification systems which have been proposed for the various patterns found in the inter- condylar fractures of distal end of humerus, we have used the classification system of Muller et al in our series as it is a standard classification system used in majority of the literature. ${ }^{3}$ This is primarily due to its simplicity and usefulness in surgical planning. Critical factors for a successful outcome are-meticulous surgical technique, stable internal skeletal fixation and early controlled post-operative mobilization. The present study found that the trans- olecranon approach with the patient in lateral position offered an excellent exposure of the articular surface. Identification and temporary fixation of the articular fragment with Kirschner wires enabled the surgeon to accurately assess the anatomy of the individual fractures. The incidence of complications in this study due to this approach was very low.

Anatomical repositioning and bone union was found to be enhanced by the use of a ' $v$ ' shaped osteotomy of the olecranon. This approach also facilitated the identification and protection of the ulnar nerve. ${ }^{4}$ Anterior trans-position was indicated when the nerve was contused from original trauma, intra operative retraction or when the medial implants caused a mechanical irritation. Emphasis was placed on the accurate restoration of the trochlea. The inherent stability provided by its congruent relationship with the greater sigmoid notch of proximal part of the ulna made its anatomical reconstruction important in restoring elbow function and off-setting later degenerative arthritis.

In those fractures in which there was loss of trochlear substance due to extensive comminution, as in type $\mathrm{C} 3$, anatomical reconstruction technically more demanding.

In the present study the technique used comprised of precontoured locking compression plates which aided in better structural stability of the fracture. It addressed every part of the distal humerus which is facilitated by the plate extensions. The 4 patients $(19.64 \%)$ had type C3 fractures had either fair or poor score due to articular comminution and metaphyseal comminution which hindered not only anatomical reduction but also immediate mobilization.

Type C3 fractures were more unstable intra-operatively after fixation when compared to type $\mathrm{C} 1$ or $\mathrm{C} 2$ fractures. Although the reduced arc of motion and joint stiffness in these fractures aided in better stability, it affected the elbow functions. We were able to compare our outcomes with a study done by Kumar et al done in $2017 .{ }^{5}$ They had included 30 patients in their study which had similar inclusion and exclusion criteria. They used only precontoured locking compression plates. The modes of injury were also comparable with that study as we had 10 patients injured due to trivial fall and 16 patients injured due to high velocity injury-road traffic accidents. They had 16 patients who were injured by fall, 13 patients injured due to road traffic accidents and 1 patient due to sports injury. The outcomes were fairly similar to the study. Excellent and good results were clubbed and compared.
They had $27(89.66 \%)$ of excellent and good results as opposed to $27(79.4 \%)$ in our study. They had two patients $(6.66 \%)$ with fair results as opposed to four $(12 \%)$ in our study. They had only one $(3.33 \%)$ patient with poor outcome and we had three (9\%).

When compared with Jupiter et al series who had 19 patients in $\mathrm{C} 3$ with 8 excellent score, 8 good score, 1fair and 2 poor score. In type $\mathrm{C} 2$ fractures we had 11 patients with 3 excellent and 8 good results out of our total results. All C2 fractures with good result had a good arc of motion but presence of mild pain and subjective complaints of few functional difficulty reduced their overall score. In Jupiter et.al series there was only 2 patients with $\mathrm{C} 2$ fracture, with one good and one excellent score. In our study there was 6 C1 patients with 3 excellent and 3 good score. ${ }^{6}$ When compared with Jupiter et al series who had 13 cases inc1fracture with 4 excellent, 5 good, 3 fair and one poor score. On long term follow up, all patients with $\mathrm{C} 1$ fracture had excellent arc of motion, good function and good radiological union. Out of 21 patients in our study $17(80.95 \%)$ patients had good $11(52.5 \%)$ / excellent 6 $(28.5 \%)$ results. This was comparable with Jupiter et al. His study of 34 patients $26(79.40 / 0)$ patients showed good $14(41 \%)$ / excellent $13(38.4 \%)$ result.

A study by Doornberg et al who had a series of 30 patients, showed good $19(63 \%) /$ excellent 7 (23\%) results. ${ }^{7}$ While Nottingham study had total of 38 patients $29(76.30 / 0)$ patients showed good 15 (39.40/0)/excellent 14 (36.84\%) results. ${ }^{8}$

The correlation we found between the functional results and the type of fractures confirm the prognostic value of A.O classification. Our mean flexion contracture was 18.01 degrees and mean arc of motion was 100.32 degrees as compared to McKee et al who had 25 degrees of mean flexion contracture and 108 degrees of mean arc of motion. Our patients were somewhat younger and our follow up was shorter when compared to Jupiter et al study. The clinical evaluation did not always correlate with the follow-up radiograph.

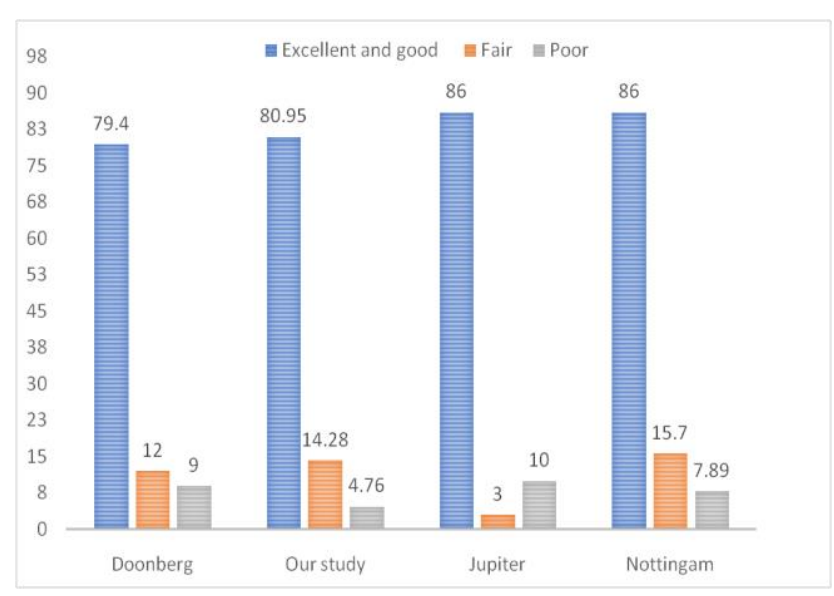

Figure 5: Comparison between studies-functional outcome. 
Mayo elbow functional scoring system is useful for it is a simple and surgeon based clinical assessment. Functional differences that were found in the excellent range of motion were rated as only good because of some discomfort noted with exertion and subjective assessment that the elbow was not normal. One patient had a poor result and 3 fair results where all of the had type c3 fractures. We had two patients $(9.52 \%)$ who needed (secondary surgery) early implant exit because of ulnar nerve irritation and $\mathrm{K}$ wire prominence as compared to McKee et al who had $6.24 \%$ out of his 25 patients who needed secondary surgery. ${ }^{9}$

Early $\mathrm{K}$ wire back out was seen in 1 case. Which was due to poor purchase in the opposite cortex. We had no nonunion of fractures in our study. The Jupiter et.al study had 2 cases $(9.52 \%)$ of nonunion. We had no olecranon nonunion, in our series all olecranon osteotomies were fixed with 2 parallel $\mathrm{k}$ wires and tension band wiring. Ulnar nerve neuritis was seen in $2(9.520 / 0)$ patients. This was due to implant prominence on the medial side. Compared to Jupiter et. al where in his study they had 5 $(14.5 \%)$ with ulnar nerve neuritis. These patients required early implant removal.

The complications were also compared with a study by Halfet et al wherein they had $10 \%$ of olecranon nonunion, $3.7 \%$ of infection and had no non unions of the fracture. ${ }^{10}$

The main limitation in our study was the sample size. Also, if this study was a comparative study between other implant choices and the pre-contoured plate, we could have drawn more conclusions regarding the outcome of fractures treated with this implant.

\section{CONCLUSION}

This study comprises of 21 patients with displaced intra articular fractures of distal humerus fractures treated by pre-contoured locking compression plate. Pre-contoured locking compression plate appears to be technically an ideal implant for comminuted osteoporotic bone providing an angle stable construct. And with proper physiotherapy, it provided results with $100 \%$ union and here by eliminating age old problems of collapse, malunion and non-union. Hence, we conclude that using pre-contoured locking compression plate produces good results and appears to be a good method of choice for management of distal humerus fracture.
Funding: No funding sources

Conflict of interest: None declared

Ethical approval: The study was approved by the institutional ethics committee

\section{REFERENCES}

1. Amir S, Jannis S, Daniel R. Distal humerus fractures: a review of current therapy concepts. Curr Rev Musculoskelet Med. 2016;9(2):199-206.

2. Kong L, Wang Y, Lu Q, Han Y, Wang F. Biomechanical properties of a novel fixation system for intra-articular distal humerus fractures: a finite element analysis. J Orthop Surg Res. 2021;16(1):674.

3. Wennergren D, Stjernström S, Möller M, Sundfeldt M, Ekholm C. Validity of humerus fracture classification in the Swedish fracture register. BMC Musculoskelet Disord. 2017;18(1):251.

4. Ebraheim NA, Andreshak TG, Yeasting RA, Saunders RC, Jackson WT. Posterior extensile approach to the elbow joint and distal humerus. Orthop Rev. 1993;22(5):578-82.

5. Kumar G, Rani S, Kumar R. Outcome of management ofdistal humerus fractures by locking compression plate. Int J Orthopedic Sci. 2017;3(3):757-64.

6. Jupiter JB, Nef1 D, Holzach P, Allgower M. Intercondylar fractures of the humerus. An operative approach. J Bone Joint Surge Am. 1985;67-A(2):22639.

7. Doornberg JN, Van Duijn PJ, Linzel D Surgical treatment of intra-articular fractures of the distal part of the humerus. Functional outcome after twelve to thirty years. J Bone Joint Surg Am. 2007;89(7):152432.

8. Holdsworth BJ, Mossad MM. Fractures of the adult distal humerus. Elbow function after internal fixation. J Bone Joint Surg Br. 1990;72(3):362-5.

9. Mckee MD, Wilson TL, Winston L. Functional outcome following surgical treatment of intraarticular distal humerus fractures through a posterior approach. J Bone Joint Surg Am. 2000;82A(12);1701-7.

10. Helfet DL, Hotchkiss RN. Intenal fixation of the distal humerus: a biomechanical comparison of methods. J Orthop Trauma. 1990;4(3):260-4.

Cite this article as: Vanchi PK, Raghav RV, Kumar MM. Functional and radiological outcomes of distal humerus fractures treated with precontoured locking compression plate. Int J Res Orthop 2022;8:209-13. 